\title{
Delisted routine eye examinations for nonrefractive eye conditions: a comparative analysis
}

\author{
William Jeon MSc, Graham E. Trope MB PhD, Richard H. Glazier MD MPH, Michael H. Brent MD, \\ Yvonne M. Buys MD, Ya-Ping Jin MD PhD
}

\section{Abstract}

Background: In 2004, Ontario delisted routine eye examinations for people aged 20-64 years, potentially encouraging patients seeking eye care to visit government-insured primary care providers (PCPs) rather than optometrists whose services had been deinsured. We investigated if utilization of PCP services for nonrefractive eye conditions increased after 2004 among Ontarians who were affected by the delisting.

Methods: We conducted a comparative analysis of the utilization of PCP services for nonrefractive eye conditions in Ontario using administrative data from 2000 to 2014 . We included participants without a visit to government-insured optometrists or ophthalmologists in the year before the study year; we excluded participants with existing diabetes. Changes in utilization before and after delisting were statistically assessed using segmented regression analysis in subgroups stratified by age, sex, rurality and neighbourhood income.

Results: A significant increase in utilization of PCP services for nonrefractive ocular diagnoses after 2004 was documented among people affected by the delisting: $17.8 \%$ (95\% confidence interval $[\mathrm{Cl}] 17.0 \%$ to $18.7 \%$ ) for people aged $20-39$ years and $11.6 \%$ $(95 \% \mathrm{Cl} 10.6 \%$ to $12.5 \%)$ for people aged $40-64$ years. This corresponds to an increase in the number of patients who visited PCPs for nonrefractive ocular diagnoses of $10690(95 \% \mathrm{Cl} 321$ to 21059$)$ for people aged $20-39$ years and 20682 (95\% $\mathrm{Cl}-94$ to 41457 ) for people aged 40-64 years. Among people aged 65 years and older (an age group not affected by the delisting), utilization of PCP services for nonrefractive ocular diagnoses was stable $(p=0.95)$ throughout the study period. Changes in utilization of PCP services for nonocular diagnoses were nonsignificant among people aged 0-19, 40-64 and 65 years and older.

Interpretation: After delisting, utilization of the services of government-funded PCPs for nonrefractive ocular diagnoses significantly increased among Ontarians affected by the delisting. The impact on ocular outcomes and the cost-effectiveness of increased use of PCPs for ocular management warrants further investigation and policy-makers' consideration.

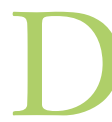

einsuring or delisting previously insured provincial health care services has been a popular government strategy in Canada to address growing health care costs. In 2004, routine eye examinations provided by optometrists and physicians for residents aged 20-64 years were delisted by the Ontario government, unless people had a medical eye condition, were on social assistance or acquired a valid referral. ${ }^{1,2}$

Routine eye examinations offer patients the opportunity both to obtain optimal vision from refractive error corrections and to have undiagnosed disease detected. The Canadian Association of Optometrists recommends that adults aged 20-39 years should undergo a routine eye examination every 2-3 years and those aged 40-64 years should do so every 2 years. ${ }^{3}$ The Canadian Ophthalmological Society recommends that patients of any age who are experiencing changes in vision, visual field or colour vision or who are experiencing physical changes to the eye should have an eye examination as soon as possible. ${ }^{4}$
Each year, about 8 million residents of Ontario are affected by delisting ${ }^{5}$ and 2.5 million of them lack any vision insurance. ${ }^{6}$ Fees for routine or comprehensive eye examinations suggested by the Ontario Association of Optometrists are

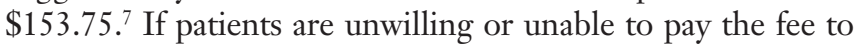
have an examination by an optometrist (a primary eye care provider), patients may attend a government-insured primary care provider (PCP, such as a family physician or pediatrician) to address their concerns.

The objective of this study was to investigate if PCP utilization for nonrefractive ocular diagnoses increased after 2004

\section{Competing interests: None declared.}

This article has been peer reviewed.

Correspondence to: Ya-Ping Jin, yaping.jin@ utoronto.ca

CMAJ Open 2020. DOI:10.9778/cmajo.20190125 
among people whose examinations were delisted. We also compared changes in PCP utilization for nonocular diagnoses and in utilization of government-insured services provided by optometrists and ophthalmologists over time to gain a better understanding of the effect of delisting on health care service utilization.

\section{Methods}

\section{Setting and study design}

The study was set in the Canadian province of Ontario, where medically necessary health services are covered for all residents by the publicly funded Ontario Health Insurance Plan (OHIP). Routine eye examinations are not considered medically necessary services but rather "additional benefits." We conducted a population-based cohort study to examine patients' yearly visits to PCPs, optometrists and ophthalmologists from Jan. 1, 2000, to Dec. 31, 2014.

\section{Data source and participants}

OHIP provider claims data from 2000 to 2014 were analyzed. We included OHIP-eligible residents of all ages without an OHIP-insured examination by an optometrist or ophthalmologist in the year before the study year; we excluded those with an existing diagnosis of diabetes. Claims for approximately 9.1 to 11.2 million residents each year were included in the analysis. We chose these inclusion and exclusion criteria because people of any age with diabetes or a suspected or diagnosed ocular disease were not affected by delisting.

The International Classification of Diseases, 9th Revision (ICD-9) ocular diagnosis codes submitted with the OHIP claims were used as a proxy measure of ocular disease. Claims for visits with ICD-9 diagnostic code 367 (myopia, astigmatism, presbyopia and other disorders of refraction and accommodation, i.e., refractive errors) were considered to comprise routine eye examinations for refractive error corrections and were excluded from the analyses. Such visits were excluded because there were rare OHIP claims for refractive errors after 2004 among Ontarians affected by delisting (causing an issue with comparability) and because refractive errors can usually be corrected by eyeglasses or contact lenses. Appendix 1, Supplemental Table S1, available at www.cmajopen.ca/content/8/3/E479/suppl/DC1, details the ICD-9 codes included in the analyses.

\section{Statistical analysis}

If a person had multiple ocular-related visits in a study year, only the earliest visit was retained, to reflect their first point of contact with the health care system. All nonrefractive ocular diagnoses were analyzed as 1 group. We calculated the yearly rate of utilization of government-insured PCP visits for nonrefractive ocular diagnoses and the yearly rate of utilization of government-insured visits to optometrists and ophthalmologists. The utilization rate was computed as the number of people with a nonrefractive ocular diagnosis who had a claim submitted to OHIP by PCPs (or optometrists or ophthalmologists) among the total number of people with a nonrefractive ocular diagnosis who had a claim submitted for a nonrefractive ocular diagnosis by all health care providers. This calculation reflected patients' realized access to eye care. ${ }^{8} \mathrm{We}$ also calculated the number of patients seeking eye care who were seen by PCPs, optometrists and ophthalmologists each year to examine if changes in utilization rate corresponded to changes in the total number of patients seeking eye care.

A comparative analysis was conducted to examine differences in utilization of the services of PCPs, optometrists or ophthalmologists for nonrefractive ocular diagnoses and in the number of patients seeking eye care who were seen by PCPs, optometrists and ophthalmologists before and after delisting. The before-after differences were statistically tested using segmented linear regression analysis. In the analysis, the yearly utilization rate (or number of patients) was divided into 2 segments (2000-2004 and 2005-2014). The 2 segments had 4 parameters: intercept $\left(\beta_{0}\right)$, baseline/ predelisting trend $\left(\beta_{1}\right)$, level change between immediately before and immediately after delisting, taking into account the trend that was predicted in the absence of the policy change $\left(\beta_{2}\right)$ and trend after delisting $\left(\beta_{3}\right)$. By examining these parameters, in particular $\beta_{2}$, we assessed if changes after 2004 were the result of chance alone or policy change. ${ }^{9-11}$ The proc arima in SAS 9.4 (SAS Institute Inc.) was used to obtain the parameters.

To examine if the observed changes in PCP utilization for ocular diagnoses similarly occurred in PCP utilization for nonocular diagnoses, we conducted a comparative analysis to look at PCP utilization for nonocular diagnoses before versus after 2004 among people affected and unaffected by delisting. Given that nonocular diagnoses include a wide range of diseases and the treatment of some of them may have been affected by the fact that OHIP delisted chiropractic and physiotherapy services, ${ }^{12,13}$ we chose dermatologic diagnoses as a representative of nonocular diagnoses for 3 reasons: similar to ocular diseases, most dermatologic diseases are not life threatening and are usually treated at outpatient clinic visits; patients with dermatologic conditions are generally not affected by the delisting of routine eye examinations, nor by the delisting of chiropractic and physiotherapy services; $;^{12,13}$ and the prevalence of dermatologic diseases is high. ${ }^{14-17}$

Physician specialty was identified by specialty code. Only visits to PCPs in an office setting were considered as PCP utilization.

Analyses were stratified by age group (patients aged 20-39 and 40-64 yr were affected by delisting; patients aged 0-19 and $\geq 65$ yr were unaffected by delisting), sex, neighbourhood income quintile and rurality of patient residence. A person's age was calculated by subtracting their year of birth from the specific study year (from 2000 to 2014). Individuals were excluded if required information was missing. Data were analyzed in the protected environment of ICES.

\section{Ethics approval}

This study was approved by the University of Toronto's Health Sciences Research Ethics Board (no. 31050). 


\section{Results}

\section{Primary care provider services}

\section{Nonrefractive ocular diagnoses}

Among people affected by delisting, a significant increase in utilization of PCP services was seen immediately after 2004 (Figure 1). For example, among patients aged 20-39 years, utilization of PCP services was $34 \%$ in 2003 and $50 \%$ in 2005 . The increased level of utilization of PCP services remained stable from 2005 until the last study year. Overall, the increase in utilization of PCP services was $17.8 \%$ (95\% confidence interval [CI] $17.0 \%$ to $18.7 \%$ ) for patients aged $20-39$ years and $11.6 \%$ (95\% CI $10.6 \%$ to $12.5 \%$ ) for patients aged $40-64$ years after delisting (Table 1). This increase corresponds to an increase in the number of patients who visited PCPs for nonrefractive ocular diagnoses of 10690 (95\% CI 321 to 21059 ) for the 20- to 39-year age group and 20682 (95\% CI -94 to 41457 ) for the 40- to 64-year age group. The increase in utilization of PCP services in these age groups after 2004 was statistically significant in men and women, in all 5 income quintiles and in urban and rural residents (Appendix 1, Supplemental Table S2).
Among people aged 0-19 years (an age group unaffected by delisting), there was a small but significant increase in PCP utilization: $2.7 \%$ (95\% CI $1.3 \%$ to $4.1 \%$ ) (Figure 1 and Table 1). In people aged 65 years and older (also unaffected by delisting), there was no significant change after delisting (Table 1).

\section{Dermatologic diagnoses}

In age groups affected and unaffected by delisting, the utilization of PCP services for dermatologic diagnoses did not change significantly after 2004 for the most part (Figure 2 and Table 1). The exception was a small increase of $1.1 \%$ between immediately before and immediately after delisting among people aged $20-30$ years, relative to the utilization rate that was predicted in the absence of the policy change.

\section{Optometric services}

Among people affected by delisting, a significant decrease in utilization of government-insured optometric services was recorded after delisting for the 20- to 39-year age group (-30.0\%, 95\% CI $-31.8 \%$ to $-28.1 \%)$, representing -76925 (95\% CI -96828 to -57021 ) fewer patients, and for the

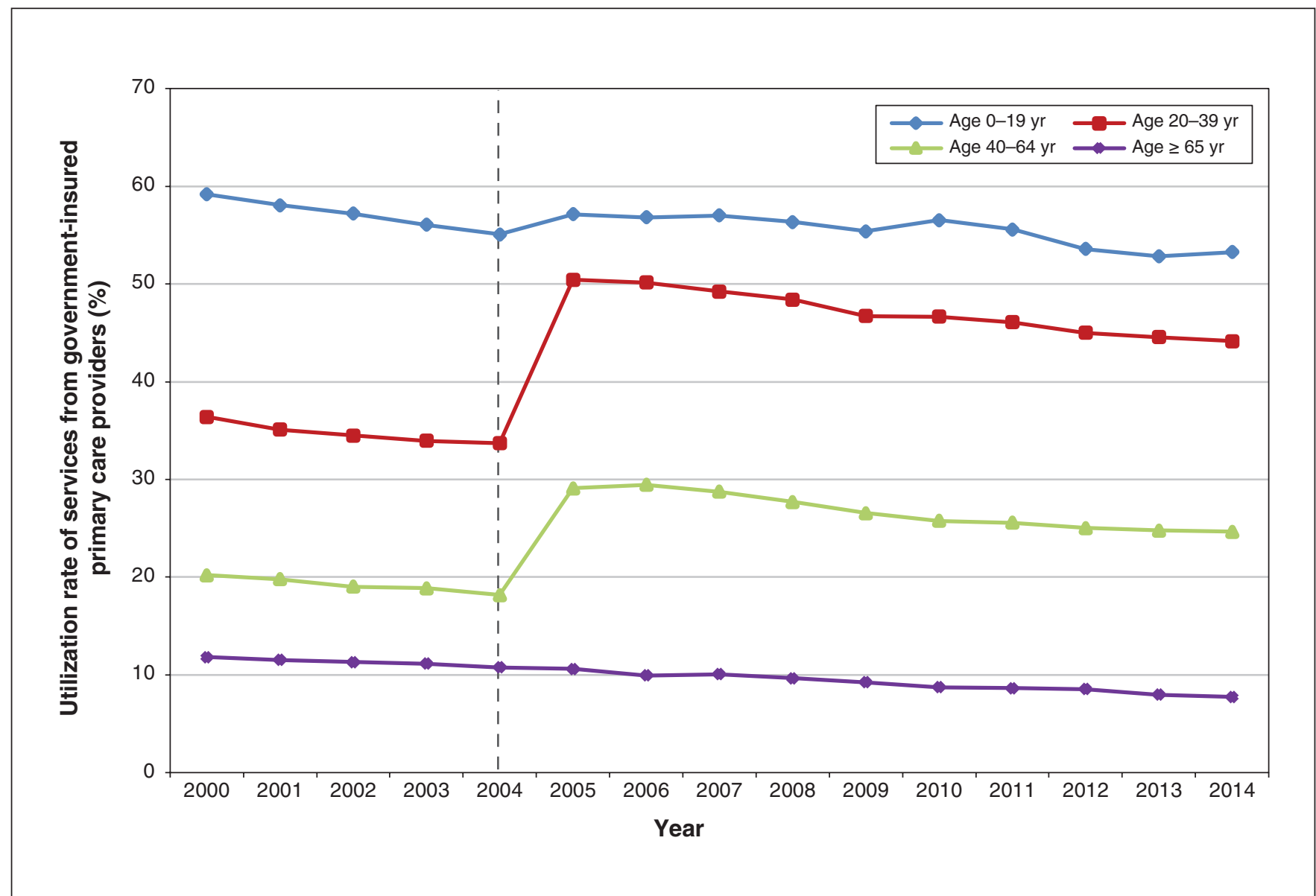

Figure 1: Utilization rate of services from government-insured primary care providers (family physicians and pediatricians) for nonrefractive ocular diagnoses from 2000 to 2014 by patient age group in Ontario. Utilization rate (\%) is defined as the number of people with a nonrefractive ocular diagnosis who had a claim submitted by primary care providers among the total number of people with a nonrefractive ocular diagnosis who had a claim submitted to the Ontario Health Insurance Plan by all health care providers. 


\begin{tabular}{|c|c|c|}
\hline Category of provider utilization; patient age, yr & Level change after 2004, $\beta_{2}(95 \% \mathrm{Cl})$ & Trend after 2004, $\beta_{3}(95 \% \mathrm{Cl})$ \\
\hline \multicolumn{3}{|l|}{ Nonrefractive ocular diagnoses } \\
\hline \multicolumn{3}{|l|}{ Primary care providers } \\
\hline $0-19$ & 2.7 (1.3 to 4.1$)$ & 0.5 (0.03 to 1.0$)$ \\
\hline 20-39 & $17.8(17.0$ to 18.7$)$ & $-0.1(-0.4$ to 0.2$)$ \\
\hline $40-64$ & 11.6 (10.6 to 12.5$)$ & $-0.1(-0.4$ to 0.2$)$ \\
\hline$\geq 65$ & $-0.01(-0.3$ to 0.3$)$ & $-0.1(-0.2$ to 0.03$)$ \\
\hline \multicolumn{3}{|l|}{ Optometrists } \\
\hline $0-19$ & $-4.3(-5.6$ to -2.9$)$ & $-0.9(-1.3$ to -0.5$)$ \\
\hline 20-39 & $-30.0(-31.8$ to -28.1$)$ & $-0.3(-0.8$ to 0.2$)$ \\
\hline $40-64$ & $-25.6(-27.0$ to -24.2$)$ & $-0.6(-1.1$ to -0.1$)$ \\
\hline$\geq 65$ & $0.7(0.1$ to 1.4$)$ & $-0.5(-0.7$ to -0.3$)$ \\
\hline \multicolumn{3}{|l|}{ Ophthalmologists } \\
\hline $0-19$ & $-0.7(-1.7$ to 0.2$)$ & $0.03(-0.2$ to 0.2$)$ \\
\hline 20-39 & 4.5 (3.7 to 5.3$)$ & $0.4(0.1$ to 0.6$)$ \\
\hline $40-64$ & $9.1(8.2$ to 10.0$)$ & $0.7(0.4$ to 1.0$)$ \\
\hline$\geq 65$ & $-0.9(-1.3$ to -0.5$)$ & $0.6(0.5$ to 0.8$)$ \\
\hline \multicolumn{3}{|l|}{ Dermatologic diagnoses } \\
\hline \multicolumn{3}{|l|}{ Primary care providers } \\
\hline $0-19$ & $-0.3(-0.7$ to 0.2$)$ & $-0.4(-0.6$ to -0.2$)$ \\
\hline 20-39 & $1.1(0.3$ to 1.9$)$ & $-0.4(-1.1$ to 0.2$)$ \\
\hline $40-64$ & $1.0(-0.2$ to 2.2$)$ & $0.4(-1.3$ to 0.4$)$ \\
\hline$\geq 65$ & $0.2(-0.7$ to 1.1$)$ & $-0.1(-0.4$ to 0.1$)$ \\
\hline
\end{tabular}

40 - to 64-year age group $(-25.6 \%, 95 \% \mathrm{CI}-27.0 \%$ to $-24.2 \%$ ), representing -141 489 (95\% CI -164353 to -118625 ) fewer patients (Figure 3 and Table 1). Among people aged 0-19 years (an age group unaffected by delisting), a small but significant decrease of $-4.3 \%$ (95\% CI $-5.6 \%$ to $-2.9 \%)$ was observed. The change among those aged 65 years and older was $0.7 \%$ (Figure 3 and Table 1 ).

\section{Ophthalmologic services}

After delisting, the utilization of the services of ophthalmologists increased by $4.5 \%$ (95\% CI $3.7 \%$ to $5.3 \%$ ) in the 20 - to 39-year age group, representing 1298 patients (95\% CI -2037 to 4633 ), and by $9.1 \%$ (95\% CI $8.2 \%$ to $10.0 \%$ ) in the 40 - to 64-year age group, representing 7991 patients (95\% CI -10153 to 26135 ) (Figure 4 and Table 1). In age groups unaffected by delisting, changes in utilization of governmentinsured ophthalmologists were $-0.7 \%$ (95\% CI $-1.7 . \%$ to $0.2 \%$ ) for people aged $0-19$ years and $-0.9 \%$ (95\% CI $-1.3 \%$ to $-0.5 \%$ ) for those aged 65 years and older (Table 1 ) between immediately before and immediately after delisting relative to the utilization rate that was predicted in the absence of the policy change.

\section{Interpretation}

Deinsurance is a government strategy designed to save money by shifting selected health care costs from government to patients. Our study suggests that many people affected by delisting circumvented this cost shifting. Instead of having a delisted optometric examination, patients seeking ocular care attended government-insured PCPs. This health-seeking behavioural change is demonstrated by 3 findings: after delisting (a) utilization of PCP services for nonrefractive ocular diagnoses increased among people in the age groups affected by delisting but remained stable among those in the age groups unaffected by delisting, (b) utilization of PCP services for nonocular diagnoses remained stable in age groups affected by delisting and (c) the significantly increased utilization of PCP services was accompanied by a significantly decreased utilization of OHIP-insured optometric services. The increased utilization of PCP services was evident among men and women, rural and urban residents, and earners at all income levels.

We believe the increased utilization of the governmentinsured services of PCPs for nonrefractive ocular diagnoses 


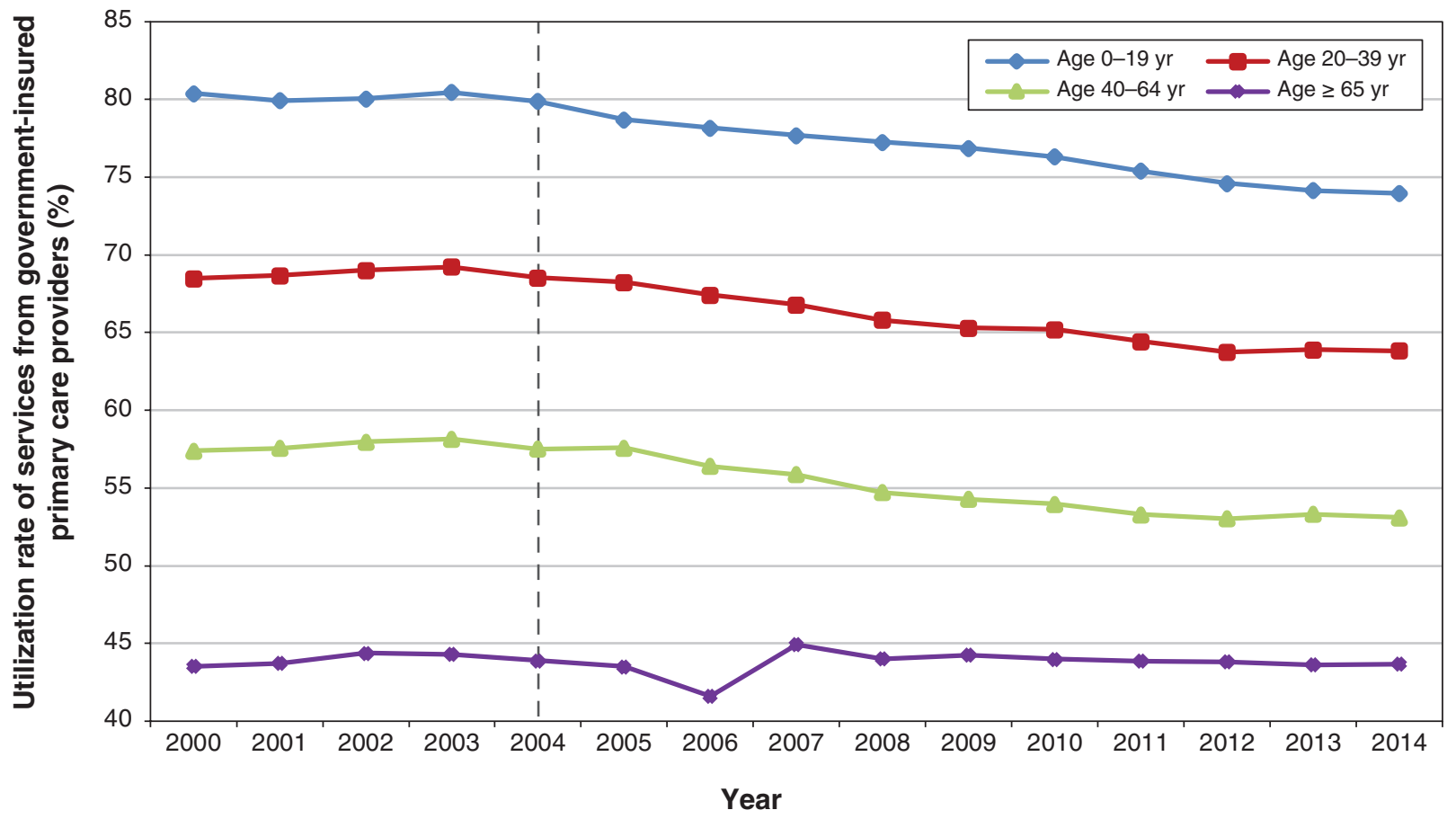

Figure 2: Utilization rate of services from government-insured primary care providers (family physicians and pediatricians) for dermatologic diagnoses from 2000 to 2014 by patient age group in Ontario. Utilization rate (\%) is defined as the number of people with a dermatologic diagnosis who had a claim submitted by primary care providers among the total number of people with a dermatologic diagnosis who had a claim submitted to the Ontario Health Insurance Plan by all health care providers.

after delisting is probably attributable to the fee charged by optometrists following delisting. Although about $60 \%$ of Ontarians of working age have some level of eyeglass insurance coverage, ${ }^{6}$ copayment is frequently required. ${ }^{6,7,18,19}$ Furthermore, nearly one-third of working-age Ontarians do not have any vision insurance and are required to pay for eye examinations fully. ${ }^{6}$ Efforts to find a way to avoid out-ofpocket expenses (e.g., a government-covered alternative for care) were probably the driving force behind the increased utilization of PCP services. However, further research is needed to confirm this hypothesis.

Given that PCPs may lack the specific equipment needed for eye care and have a limited knowledge of eye diseases, PCPs usually refer patients requiring eye care to ophthalmologists or optometrists. Upon referral, people affected by delisting are eligible to receive OHIP-insured services provided by ophthalmologists or optometrists. ${ }^{2}$ This pathway to eye care leads to duplicate OHIP billings (1 for PCPs and the other for ophthalmologists or optometrists). Furthermore, this pathway limits PCPs from seeing other patients for whom they have the skill set to provide care. Unlike PCPs, optometrists are specifically trained to deal with primary eye care and are equipped with specialized eye instrumentation (e.g., slit lamps) for comprehensive ocular examinations. Although delisting reduced the costs of optometric services for the government, this decrease was probably offset by costs to the OHIP system from increased utilization of governmentinsured PCP services. Further research is needed to determine the financial impact of delisting on the health system.

Several prior studies have evaluated the effects of the delisting of eye examinations. Using self-reported data, Stabile and Ward demonstrated that delisting reduced the probability that a person would visit an optometrist. ${ }^{20}$ Also using self-reported data, Jin and associates reported that delisting preferentially affected people who were socially disadvantaged in terms of the combined utilization of optometrists and ophthalmologists. ${ }^{21}$

Ontario's delisting should not have affected people with diabetes. ${ }^{2}$ Unexpectedly, Kiran and colleagues reported that the rate of eye examinations significantly decreased among Ontarians with diabetes aged 40-64 years. ${ }^{22}$ The authors concluded that this was an unintended consequence of delisting, perhaps due to a misunderstanding of the changed policy by health care providers and the public.. ${ }^{22}$ In the United Kingdom, the number of referrals and the rate of glaucoma detection declined by nearly $20 \%$ after the introduction of a sight test fee. ${ }^{23}$ None of these prior studies examined whether delisting affected utilization of PCP services. 


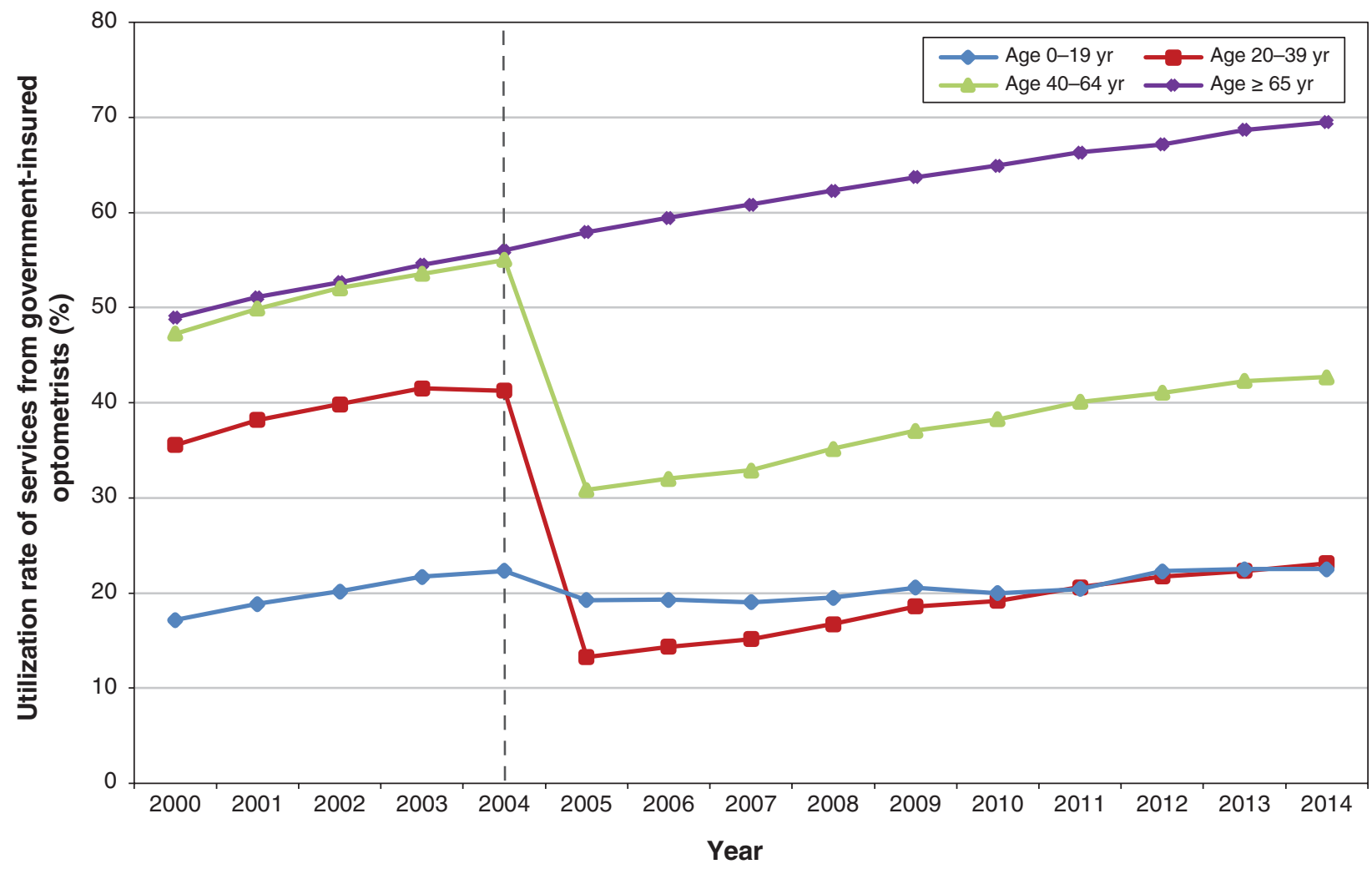

Figure 3: Utilization rate of services from government-insured optometrists from 2000 to 2014 by patient age group in Ontario. Utilization rate $(\%)$ is defined as the number of people with a nonrefractive ocular diagnosis who had a claim submitted by optometrists among the total number of people with a nonrefractive ocular diagnosis who had a claim submitted to the Ontario Health Insurance Plan by all health care providers.

Ontario was the most recent Canadian province to delist routine eye examinations. Many other provinces delisted routine eye examinations earlier. ${ }^{24}$ Given that all Canadian provinces have a universal health coverage plan, the findings of this study are probably generalizable to other provinces. Furthermore, all Canadian provinces currently face budget deficits and may look favourably at delisting or privatizing a variety of health care services. This study provides evidence of unintended consequences of delisting services in relation to increased utilization of PCPs that could be very timely in the current environment.

\section{Limitations}

There are limitations to this study. First, the validity of ICD-9 codes for ocular diagnoses in the OHIP database is mostly unknown. We minimized this issue by grouping all ocular diagnoses together. We believe the probability is high that OHIP physicians correctly code the affected organ, in this case the eye. Several studies support this assumption: (a) the sensitivity of coding for glaucoma and diabetes in health administrative databases has been reported to range from $76 \%$ to $90 \%$ and the specificity from $92 \%$ to $94 \%, 25,26$ (b) the agreement between billing data and patients' corresponding medical records on common ocular conditions has been reported to be as high as $92 \%-100 \%{ }^{27}$ and (c) PCPs' ability to recognize the eye as the diseased organ compared with ophthalmologist diagnoses was greater than $92 \% .28,29$

A second limitation is that the OHIP database does not include eye care services paid for out of pocket or by private or employment-associated insurance. Ontarians who received such services were thus not included in the analyses. However, if a patient were to be diagnosed with or suspected to have an ocular disease in their privately insured or employmentinsured visits, this patient would subsequently have become eligible for OHIP-insured services provided by ophthalmologists or optometrists and be included in the analyses.

Third, before delisting, nonrefractive diagnoses identified in routine eye examinations were included in the analyses. After delisting this would have been unlikely to have occurred. However, we do not think that the few cases of nonrefractive diagnoses discovered during routine eye examinations after delisting are the source of the increased PCP utilization 


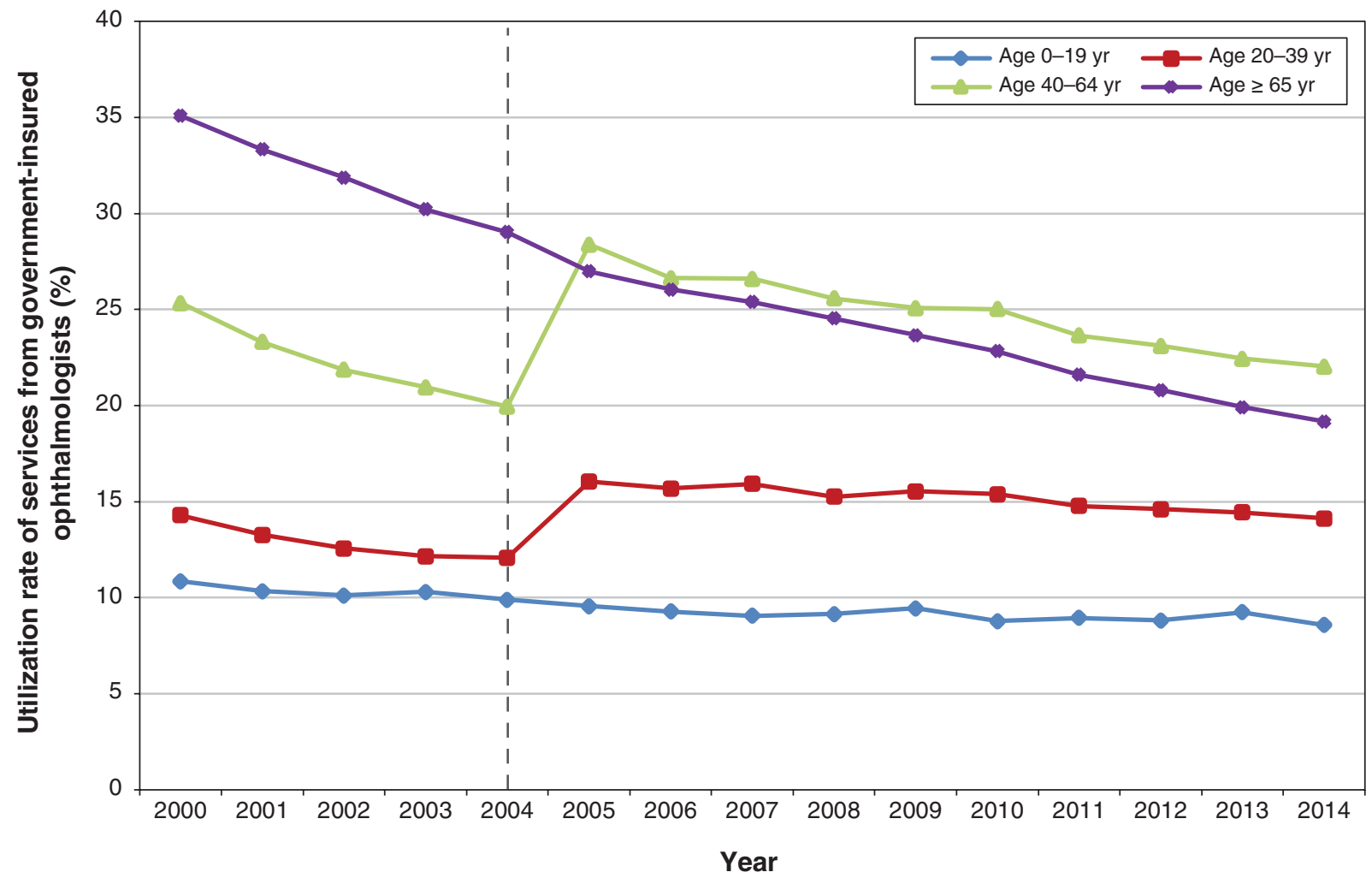

Figure 4: Utilization rate of services from government-insured ophthalmologists from 2000 to 2014 by patient age group in Ontario. Utilization rate $(\%)$ is defined as the number of people with a nonrefractive ocular diagnosis who had a claim submitted by ophthalmologists among the total number of people with a nonrefractive ocular diagnosis who had a claim submitted to the Ontario Health Insurance Plan by all health care providers.

reported, because PCPs usually do not perform routine eye examinations and the detection of ocular disease diagnoses at routine eye examinations after delisting was significantly reduced, rather than increased.

Lastly, there were insufficient data points to test the significance of differences in level change after 2004 between subgroups using interaction terms in the primary model (Appendix 1, Supplemental Table S2). Consequently, we cannot assess whether the differences between the small but significant $2.7 \%$ increase in PCP utilization among people aged 0-19 years (unaffected by delisting) and the $17.8 \%$ increase among people aged 20-39 and 40-64 years (affected by delisting) are statistically significant.

\section{Conclusion}

This study investigated the impact of delisted routine eye examinations on utilization of PCPs. The results suggest that delisting is associated with increased government-funded PCP utilization. The monetary and human resource cost of increased use of PCPs for ocular management and the influence on ocular outcomes warrant further investigation, given the lack of equipment and training in eye diseases among
PCPs. Policy-makers should be aware of the unintended consequences of increased reliance on PCPs after delisting eye examinations. Delisting may not always result in the expected cost savings.

\section{References}

1. Changes to eye care services for patients age 20 to 64 years [bulletin]. Toronto: Ontario Ministry of Health and Long-Term Care; 2004. Available: http://www.health.gov.on.ca/en/pro/programs/ohip/bulletins/8000/ bul8089.pdf (accessed 2019 Nov. 28).

2. Changes to OHIP coverage for eye care services. Toronto: Ontario Ministry of Health and Long-Term Care; 2004. Available: http://www. familyoptometryptbo.ca/librairie/documents/ChangestoOHIPCoveragefor EyeCareServices_000.pdf (accessed 2019 Nov. 28).

3. Frequency of eye examinations. Ottawa: Canadian Association of Optometrists. Available: https://opto.ca/health-library/frequency-of-eye-examinations (accessed 2019 Nov. 28)

4. Clinical Practice Guideline Expert Committee. Canadian Ophthalmological Society evidence-based clinical practice guidelines for the periodic eye examination in adults in Canada. Can 7 Ophthalmol 2007;42:39-45, 158-63.

5. Focus on geography series, 2011 census. Province of Ontario. Ottawa: Statistics Canada; modified 2019 Mar. 26. Available: http://www12.statcan.gc.ca/ census-recensement/2011/as-sa/fogs-spg/Facts-pr-eng. cfm?Lang=eng\&GC=35 (accessed 2019 Nov. 28).

6. Ngo G, Trope G, Buys Y, et al. Significant disparities in eyeglass insurance coverage in Canada. Can 7 Ophthalmol 2018;53:260-5.

7. Suggested schedule of professional fees, Ontario: effective June 1, 2012. Toronto: Association of Optometrists. 
8. Andersen RM. Revisiting the behavioral model and access to medical care: Does it matter? 7 Health Soc Behav 1995;36:1-10.

9. Penfold RB, Zhang F. Use of interrupted time series analysis in evaluating health care quality improvements. Acad Pediatr 2013;13(Suppl):S38-44

10. Bernal JL, Cummins S, Gasparrini A. Interrupted time series regression for the evaluation of public health interventions: a tutorial. Int $\mathcal{F}$ Epidemiol 2017;46:348-55.

11. Wagner AK, Soumerai SB, Zhang F, et al. Segmented regression analysis of interrupted time series studies in medication use research. 7 Clin Pharm Ther 2002;27:299-309.

12. OHIP change to coverage for chiropractors. Toronto: Ontario Ministry of Health and Long-Term-Care; 2005. Available: http://www.health.gov.on.ca/ english/public/pub/ohip/chiropractic.html (accessed 2019 Nov. 28).

13. Changes to OHIP-insured physiotherapy services: effective April 1, 2005. Toronto: Ontario Ministry of Health and Long-Term-Care; 2005. Available: http://www.health.gov.on.ca/en/pro/programs/ohip/bulletins/3000/0324/physio_ poster.pdf (accessed 2019 Nov. 28).

14. Stern RS, Johnson ML, DeLozier J. Utilization of physician services for dermatologic complaints. The United States, 1974. Arch Dermatol 1977;113:1062-6.

15. Baibergenova A, Shear NH. Skin conditions that bring patients to emergency departments. Arch Dermatol 2011;147:118-20.

16. Hay RJ, Johns NE, Williams HC, et al. The global burden of skin disease in 2010: an analysis of the prevalence and impact of skin conditions. 7 Invest Dermatol 2014;134:1527-34.

17. Peart JM, Sharma P, Kovarik CL, et al. Prevalence of dermatologic disease in an urban emergency department: a cross-sectional study. 7 Am Acad Dermatol 2015;72:920-1.

18. Insurance for professionals: valuable protection designed for members of participating associations. Waterloo (ON): Manulife Financial. Available: https://www1.manulife. com/can/affinity/affinity.nsf/LookupFiles/DownloadableFilepp.ehc.bro/\$File/ pp_ehc_bro.pdf (accessed 2019 Nov. 28).

19. Great-West Life. Visioncare benefits. Winnipeg: Great-West Life. Available: https://www.greatwestlife.com/flexbox/product-details/vision (accessed 2020 May 19).

20. Stabile M, Ward C. The effects of delisting publicly funded health care services. Kingston (ON): McGill-Queen's University Press; 2006:83-110.

21. Jin YP, Buys YM, Hatch W, et al. De-insurance in Ontario has reduced use of eye care services by the socially disadvantaged. Can 7 Ophthalmol 2012; 47:203-10

22. Kiran T, Kopp A, Moineddin R, et al. Unintended consequences of delisting routine eye exams on retinopathy screening for people with diabetes in Ontario, Canada. CMA7 2013;185:E167-73.

23. Laidlaw DA, Bloom PA, Hughes AO, et al. The sight test fee: effect on ophthalmology referrals and rate of glaucoma detection. BM7 1994:309:634-6.

24. Foundations for a Canadian vision health strategy: towards preventing avoidable blindness and promoting vision health. Toronto: National Coalition for Vision Health; 2007:83.

25. Wilchesky M, Tamblyn RM, Huang A. Validation of diagnostic codes within medical services claims. 7 Clin Epidemiol 2004;57:131-41.

26. Hux JE, Ivis F, Flintoft V, et al. Diabetes in Ontario: determination of prevalence and incidence using a validated administrative data algorithm. Diabetes Care 2002;25:512-6.

27. Muir KW, Gupta C, Gill P, et al. Accuracy of international classification of diseases, ninth revision, clinical modification billing codes for common ophthalmic conditions. 7AMA Ophthalmol 2013;131:119-20.

28. Sheldrick JH, Vernon SA, Wilson A. Study of diagnostic accord between general practitioners and an ophthalmologist. BM7 1992;304:1096-8.

29. Pierscionek TJ, Moore JE, Pierscionek BK. Referrals to ophthalmology: optometric and general practice comparison. Opbthalmic Pbysiol Opt 2009; 29:32-40.
Affiliations: Institute of Medical Science (Jeon, Trope, Glazier, Brent, Jin) and Department of Ophthalmology and Vision Sciences (Trope, Brent, Buys, Jin), University of Toronto; Department of Family and Community Medicine (Glazier), University of Toronto and St. Michael's Hospital; ICES (Glazier), Toronto, Ont.

Contributors: William Jeon contributed to designing the study, curating and analyzing the data and drafting the article. Graham Trope, Richard Glazier, Michael Brent and Yvonne Buys contributed to designing the study. Ya-Ping Jin contributed to designing the study, analyzing the data and drafting the article. All authors analyzed the data, revised the article critically for important intellectual content, approved the final version to be published and agreed to be accountable for all aspects of the work.

Funding: This study made use of deidentified data from the ICES Data Repository, which is managed by ICES with support from its funders and partners: Canada's Strategy for Patient-Oriented Research (SPOR), the Ontario SPOR Support Unit, the Canadian Institutes of Health Research and the Government of Ontario. Parts of this material are based on data and information compiled and provided by the Canadian Institute for Health Information (CIHI). This project was financially supported by the Department of Ophthalmology and Vision Sciences, University of Toronto, Vision Science Research Program (VSRP) and the Canadian National Institute for the Blind (CNIB). Richard Glazier is supported as a Clinician Scientist in the Department of Family and Community Medicine at the University of Toronto and St. Michael's Hospital.

Data sharing: The data set from this study is held securely in coded form at ICES. While data-sharing agreements prohibit ICES from making the data set publicly available, access may be granted to those who meet prespecified criteria for confidential access, available at www.ices.on.ca/DAS. The full data-set creation plan and underlying analytic code are available from the authors upon request, with the understanding that the computer programs may rely upon coding templates or macros that are unique to ICES and are therefore either inaccessible or may require modification.

Acknowledgements: The authors thank Drs. Karen Tu, Nav Persaud and Sisira Sarma for their comments and suggestions on this study.

Meeting presentations: The study abstract was presented at the Institute of Medical Science Scientific Day, University of Toronto, May 2017, and at the Department of Ophthalmology and Vision Sciences, University of Toronto, May 2017.

Disclaimer: This study contracted ICES Data \& Analytic Services (DAS) and used deidentified data from the ICES Data Repository, which is managed by ICES with support from its funders and partners: Canada's Strategy for Patient-Oriented Research (SPOR), the Ontario SPOR Support Unit, the Canadian Institutes of Health Research and the Government of Ontario. The opinions, results and conclusions reported are those of the authors. No endorsement by ICES or any of its funders or partners is intended or should be inferred.

Supplemental information: For reviewer comments and the original submission of this manuscript, please see www.cmajopen.ca/content/8/3/ E479/suppl/DC1. 